\section{BMJ Open} Ophthalmology

\title{
Prevalence and associated risk factors of diabetic retinopathy and macular oedema in patients recently diagnosed with type 2 diabetes
}

Enrique O Graue-Hernandez, ${ }^{1}$ David Rivera-De-La-Parra, ${ }^{2}$ Sergio Hernandez-Jimenez, ${ }^{3}$ Carlos A Aguilar-Salinas, ${ }^{4}$ David Kershenobich-Stalnikowitz, ${ }^{5}$ Aida Jimenez-Corona (D) 6,7

To cite: Graue-Hernandez E0, Rivera-De-La-Parra D, Hernandez-Jimenez S, et al. Prevalence and associated risk factors of diabetic retinopathy and macular oedema in patients recently diagnosed with type 2 diabetes. BMJ Open Ophthalmology 2020;5:e000304. doi:10.1136/ bmjophth-2019-000304

Part of this study was presented as an oral presentation at the 2016 World Ophthalmology Meeting, 5-9 February 2016, Guadalajara, Mexico.

Received 22 May 2019 Revised 18 January 2020 Accepted 1 February 2020

\section{Check for updates}

\section{(C) Author(s) (or their} employer(s)) 2020. Re-use permitted under CC BY-NC. No commercial re-use. See rights and permissions. Published by BMJ.

For numbered affiliations see end of article.

Correspondence to Dr Aida Jimenez-Corona; aidaajc@gmail.com

\section{ABSTRACT}

Objective To determine the prevalence of diabetic retinopathy (DR) and diabetic macular oedema (DME) and their associated risk factors in patients recently diagnosed with type 2 diabetes.

Methods and analysis We carried out a cross-sectional study from April 2014 to August 2017. We included patients aged $\geq 18$ years. Diabetes was defined as fasting plasma glucose of $>7.8 \mathrm{mmol} / \mathrm{L}$ or 2 -hour postload plasma glucose of $>11.1 \mathrm{mmol} / \mathrm{L}$. Non-mydriatic fundus examination with a digital-fundus camera was performed. Three images centred in the macula, optic disc and temporal to the macula were obtained and graded according to the Scottish Scale Classification of Diabetic Retinopathy.

Results 1232 patients (mean age 51.5 years) with a diabetes duration of $0-5$ years were examined. Ageadjusted and sex-adjusted prevalence of DR and DME was $17.4 \%(95 \% \mathrm{Cl} 15.3 \%$ to $19.6 \%)$ and $6.6 \%(95 \% \mathrm{Cl} 5.4 \%$ to $8.2 \%$ ), respectively. DR was associated with diabetes duration (OR per year $=1.20, p<0.001$ ), haemoglobin $A 1 c$ ( $\mathrm{HbA1c}$ ) from 7.0 to $8.9(\mathrm{OR}=2.19, \mathrm{p}<0.001), \mathrm{HbA1c} \geq 9$ $(\mathrm{OR}=2.98, \mathrm{p}<0.001)$ and systolic blood pressure (SBP) $(0 R=1.16$ per $5 \mathrm{~mm} \mathrm{Hg}, p<0.001)$. DME was associated with diabetes duration (OR per year $=1.26, p<0.01$ ), $\mathrm{HbA} 1 \mathrm{C}$ from 7.0 to $8.9(0 R=2.26, p<0.05), H b A 1 c \geq 9(0 R=2.38$, $\mathrm{p}<0.01$ ), SBP (OR per $\mathrm{mm} \mathrm{Hg}=1.15, \mathrm{p}<0.001$ ) and albuminuria $(\mathrm{OR}=2.45, \mathrm{p}<0.01)$.

Conclusion Our study contributes to the evidence of progressive increase in DR and DME risk in early stages of diabetes, supporting the urgent need for early screening.

\section{INTRODUCTION}

Diabetes is an increasingly prevalent global health problem. Worldwide nearly $8.8 \%$ of adults (ie, 412 million people) have diabetes. ${ }^{1}$ Mexico is among the countries most affected by the diabetes epidemic, with a prevalence of type 2 diabetes of $9.4 \%$ in $2016 .^{2}$ Estimations show that the prevalence of diabetes roughly doubles every decade. Projected rates on three age-specific incidence scenarios suggest that diabetes prevalence among adults older

\section{Key messages}

What is already known about this subject?

- Available evidence shows a high prevalence of diabetic retinopathy (DR) and diabetic macular oedema (DME) in patients with recent diagnosis.

What are the new findings?

- This study demonstrates a constant increment on the prevalence of DR from 0 to 5 years of diabetes duration, whereas for DME, the increment was more evident from 0 to 3 years of diabetes duration.

How might these results change the focus of research or clinical practice?

In subjects with recent diagnosis of diabetes and without incapacitant complications due to this condition, haemoglobin A1c, albuminuria and hypertension constitute key factors in the development of DR and DME. Strategies to optimise the metabolic control in these group are required to prevent or delay retinal complications opportunely.

than 20 years may reach $13.7 \%-22.5 \%$ by 2050, thus affecting 15-25 million individuals, with a lifetime risk of one in three to one in two. ${ }^{3}$ As in other low-income countries, in Mexico, for each person with known diabetes diagnosis there is about one person who has the disease but does not know it; then there is a wide time interval between the onset of type 2 diabetes and its detection, which in turn increases the likelihood of diabetes complications, such as DR.

Diabetic retinopathy (DR) is one of the most common and severe microvascular complications of diabetes and the leading cause of irreversible blindness. The estimated global prevalence of DR is $34.6 \%^{4}$; however, according to estimations, it will develop in more than $75 \%$ of persons within $15-20$ years of diagnosis of diabetes. The prevalence of DR is expected to increase, and the number 
of people at risk of vision loss is predicted to double by the year 2030, along with the increasing rate of the diabetes epidemic. In Mexico, the prevalence of DR varies between $38.9 \%^{5}$ and $60.1 \%^{6}$; yet, none of the national studies have focused on DR and diabetic macular oedema (DME) prevalence in recently diagnosed type 2 diabetes.

Several studies support the evidence that diabetes duration, haemoglobin A1c (HbA1c) and blood pressure are the key factors in the development of DR; nevertheless, keeping normal glycaemic levels does not guarantee that the disease will stop progressing. ${ }^{4-9}$ Thus, additional factors may potentially have a causal role. Recent evidence supports the idea that non-traditional lipid measures are stronger risk markers of DR than total cholesterol (TC) and triglyceride (TG) levels. ${ }^{10}$ Others systemic risk factors for DR include diabetic nephropathy, obesity, anaemia, and markers of systemic inflammation and endothelial dysfunction. Ocular risk factors for DR include previous cataract surgery, which is associated with the progression of DR and the development of DME, and myopic refractive error, which appears to be protective. ${ }^{11}{ }^{12}$ In terms of genetic factors, heritability estimates of $25 \%-50 \%$ have been reported in patients with type 1 diabetes who have proliferative DR, and epigenetic mechanisms may play a role in this pathogenesis. ${ }^{13}$

While DME can occur independently of DR, it appears to be strongly associated with the severity of DR. Systemic risk factors for DME are hyperglycaemia, diabetes duration, hypertension and dyslipidaemia. Genetic factors have also been implicated and many candidate genes have been proposed. ${ }^{1314}$ In this study, we aimed to estimate the prevalence of DR and DME and their associated risk factors in patients recently diagnosed with type 2 diabetes.

\section{METHODS}

\section{Study population}

Individuals were enrolled at a comprehensive care centre for patients with diabetes (Centro de Atención Integral del Paciente con Diabetes) from April 2014 to August 2017. Details about the implementation and operation of this diabetes care centre have been published elsewhere. ${ }^{15}$ Briefly, inclusion criteria are diagnosis of type 2 diabetes within the past 5 years and ages $18-70$ years. Exclusion criteria are cognitive impairment, presence of chronic kidney disease, coronary heart disease, stroke, foot ulcers or amputations, psychiatric disorders, current smoking, drug or alcohol abuse, and immediate surgical treatment that limits moderate physical activity. Elimination criteria are pregnancy and morbidities requiring hospitalisation.

\section{Data collection}

All participants underwent a standardised examination. Data on age, history of diabetes and hypertension, anthropometric parameters, diet and physical activity were obtained through a standardised questionnaire. Anthropometric measurements were taken with each subject wearing light clothing and no shoes. Body mass index
(BMI) was calculated as weight $(\mathrm{kg})$ divided by squared height $(\mathrm{m})$. Waist circumference (WC) was measured at the level of the umbilicus $(\mathrm{cm})$. Systolic blood pressure (SBP) and diastolic blood pressure (DBP) were measured three times while participants were seated, and the average of the last two measurements was used. Type 2 diabetes was defined as fasting plasma glucose of $\geq 7.0 \mathrm{mmol} / \mathrm{L}$ or 2-hour postload plasma glucose of $\geq 11.1 \mathrm{mmol} / \mathrm{L}$ or previous diagnosis by a health professional. ${ }^{16}$ Diabetes duration was defined as years from diagnosis at the time the patient was included in the study. For analytical purposes, duration was further stratified into $<1$ year, $1-2$ years and 3-5 years. Hypertension was defined as SBP of $\geq 140 \mathrm{~mm} \mathrm{Hg}$ or DBP of $\geq 90 \mathrm{~mm}$ $\mathrm{Hg}$ or taking antihypertensive medication. ${ }^{17}$ Visual acuity was defined according to the following pinhole-corrected visual acuity thresholds: normal vision of $<0.26 \operatorname{LogMAR}$ (Snellen scale score of $<20 / 40$ ), mild impairment of $<0.26$ to $<0.44$ (Snellen scale score of $\geq 20 / 40$ to $<20 / 60$ ), severe impairment of $\geq 0.44$ to $<0.96$ (Snellen scale score of $\geq 20 / 60$ to $<20 / 200$ ) and blindness of $\geq 0.96$ (Snellen scale score of $\geq 20 / 200) .{ }^{18}$ Blood samples were collected after an overnight fast of 8-12 hours for the determination of plasma glucose, $\mathrm{HbAlc}$, TC, TG, high-density lipoprotein cholesterol and low-density lipoprotein cholesterol, and creatinine concentrations. Urine albumin-to-creatinine ratio (ACR) was determined and microalbuminuria (ACR $>30-300 \mathrm{mg} / \mathrm{g}$ ) and macroalbuminuria ACR $>300 \mathrm{mg} / \mathrm{g}$ ) were defined. All analyses were performed at the Central Laboratory at the National Institute of Medical Sciences and Nutrition, Salvador Zubiran, in Mexico City, Mexico.

\section{Assessment of retinopathy and macular oedema}

All cases with DR and DME were evaluated by a retina specialist. Examination included visual acuity, nonmydriatic photographs and biomicroscopic examination to assess the macula. Visual capacity was measured with a digital screen using a LogMAR chart, and anterior segment examination was carried out with an SL-D2 Topcon (Tokyo, Japan) slit lamp. Non-mydriatic photographs were taken with a digital retinal (DRS) non-mydriatic camera (Centervue, Padova, Italy), and three $45^{\circ}$ images centred in the macula, optic disc and temporal to the macula, respectively, were obtained. If the quality of photographs was not appropriate, a pharmacological dilation with one drop of tropicamide $0.8 \%$ and phenylephrine $5 \%$ was performed.

\section{Grading of retinal photographs}

Two standardised readers graded the retinal photographs. Previously, a subset of photographs of 60 eyes (by duplicate) was assessed for intraobserver and interobserver variations, obtaining a kappa of 0.88 . The photographs were evaluated in a masked manner to minimise any possible classification bias. The final diagnosis for each patient was determined from the grading of the worse eye. The minimum criterion for the diagnosis of DR was the presence of at least one definite microaneurysm in 
any field photographed. DR was classified according to the Scottish Diabetic Retinopathy Grading Scale as follows: R0 (no visible retinopathy), R1 (mild retinopathy), R2 (observable background retinopathy), R3 (referable background retinopathy), R4 (proliferative retinopathy) and R6 (inadequately assessed retinopathy). DME was classified as M0 (no maculopathy), M1 (observable maculopathy), M2 (referable maculopathy) and M6 (inadequately assessed maculopathy) according to the same grading scale. ${ }^{19} 20$

\section{Patient and public involvement}

Patients were not involved in the design, recruitment or conduction of the study.

\section{Statistical analysis}

Comparisons of different risk factors between persons with and without DR and with and without DME were performed using $\chi^{2}$ for categorical variables, Student's t-test for mean (with SDs), comparison of rank-sum Wilcoxon's tests for medians (with IQRs) and comparison for continuous variables, when appropriate. The main variables included in the analysis were age at diagnosis of diabetes (as continuous and dichotomous $(<40$ and $\geq 40$ years) variables), diabetes duration (as continuous and ordinal $(<1$, from 1 to 2 and $\geq 3$ years) variables), HbAlc (as continuous and ordinal $(<7 \%, 7 \%-8.9 \%$ and $\geq 9 \%$ ) variables), BMI (as a continuous variable), WC (as continuous and dichotomous ( $m e n \geq 102$, women $\geq 88$ and men $<102$, women $<88$ ) variables), SBP and DBP (as continuous variables), albuminuria (as categorical (normal, microalbuminuria and macroalbuminuria) and dichotomous (normal and albuminuria) variables), visual capacity in the better eye (as nominal (normal, moderate visual impairment, severe visual impairment and blindness) variable), and hypoglycaemic and antihypertensive medications. Unadjusted, stratified, and age-adjusted and sex-adjusted prevalences of DR and DME and their $95 \%$ CIs) were estimated by logistic regression analysis. To compare the differences on prevalence, $\chi^{2}$ and $\chi^{2}$ for trend were used when appropriate. The associated risk factors for DR and DME were examined by multiple robust logistic regression analysis, calculating ORs and their $95 \%$ CIs. Models with the whole sample and stratified by diabetes duration were done. The model fits were tested by Hosmer-Lemeshow goodness of fit. The evaluation of outliers and influence statistics was also performed. All analyses were performed using STATA/ MP V.15.1.

\section{RESULTS}

\section{Description of the study population}

Of 1232 patients included in this study, 544 (44.2\%) were men (mean age 51.5 years, SD 10) with a median duration of diabetes of 1 year (range $0-5$ ). DR occurred in at least one eye in $17.3 \%(\mathrm{n}=213)$ and DME in $6.7 \%$ $(\mathrm{n}=82)$ of patients, whereas bilateral DR was observed in $54.5 \%(116 / 213)$ and bilateral DME in 50.0\% (41/82) of patients. Comparison of patients with and without DR showed that the proportion of hypertension and albuminuria was significantly higher among those with DR than among those without. Patients with DR also had longer diabetes duration and higher HbAlc compared with patients without DR (table 1). As for patients with DME, they had longer diabetes durations (median 3 (IQR $1-4)$ vs 1 (IQR 0-3) years, respectively), had more hypertension ( $45.1 \%$ vs $34.9 \%$, respectively) and had more albuminuria (38.3\% vs $14.4 \%$, respectively) compared with patients without DME. Individuals with DME also had higher HbAlc between $7 \%$ and $8.9 \% \quad(31.7 \%$ vs $25.6 \%$, respectively) and HbA1c of $\geq 9 \%$ (50.0\% vs $34.3 \%$, respectively) than persons without DME.

\section{Prevalence of DR and macular oedema}

Prevalence of both DR and DME increased per each year of diabetes duration (figure 1). The prevalence of DR increased significantly with HbAlc level: $9.2 \%$ (95\% CI $6.9 \%$ to $12.2 \%$ ) for $\mathrm{HbAlc}<7 \%, 19.4 \%$ (95\% CI $15.4 \%$ to $24.1 \%$ ) for HbAlc $7 \%-8.9 \%$ and $24.6 \%$ (95\% CI $20.8 \%$ to $28.9 \%$ ) for $\mathrm{HbA1c} \geq 9 \%$ ( $\mathrm{p}_{\text {trend }}<0.001$ ). After stratification by diabetes duration, the prevalence of DR was greater in the presence of higher levels of HbAlc, hypertension and albuminuria (table 2).

With respect to DME, the prevalence increased with level of HbA1c: $3.1 \%$ (95\% CI $1.9 \%$ to $5.2 \%$ ) for $\mathrm{HbA} 1 \mathrm{c}<7 \%, 8.1 \%$ (95\% CI $5.6 \%$ to $11.7 \%$ ) for $\mathrm{HbAlc}$ $7 \%-8.9 \%$, and $9.4 \%$ (95\% CI $7.0 \%$ to $12.6 \%$ ) for $\mathrm{HbA1c} \geq 9 \%\left(\mathrm{p}_{\text {trend }}<0.001\right)$. Prevalence was also higher in persons with albuminuria. After stratification by diabetes duration, the prevalence of DME was higher in the presence of albuminuria for all categories of diabetes duration (table 2).

\section{Risk factors associated with diabetic retinopathy and macular oedema}

In multiple logistic regression, the probability of DR increased 20\% per each year of diabetes duration (95\% CI $1.10 \%$ to $1.32 \%$ ) and was higher in patients with HbA1c of $7.0 \%-8.9 \%(\mathrm{OR}=2.19,95 \%$ CI $1.43 \%$ to $3.35 \%)$ and in those with HbAlc of $\geq 9 \%$ (OR=2.98, 95\% CI $2.01 \%$ to $4.42 \%$ ) compared with patients with HbAlc of $<7 \%$. The probability of DR in persons with higher SBPs increased significantly (OR per $5 \mathrm{~mm} \mathrm{Hg}=1.16,95 \%$ CI 1.10 to 1.22 ) after adjustment for age at the time of diabetes diagnosis, sex and use of antihypertensive medication. In stratified analysis by diabetes duration, the magnitude of association between DR and HbAlc categories was stronger in patients with a duration of $3-5$ years $(\mathrm{OR}$ for $\mathrm{HbAlc}$ $7 \%-8.9 \%=3.37,95 \%$ CI $1.52 \%$ to $7.50 \%$ and OR for $\mathrm{HbA} 1 \mathrm{c} \geq 9 \%=6.22,95 \%$ CI $2.96 \%$ to $13.09 \%$ ) compared with patients with a duration $<3$ years $(\mathrm{OR}=6.75,95 \% \mathrm{IC}$ 2.98-15.30). The association was similar with SBP in both strata (table 3).

As for DME, the probability of this condition increased with diabetes duration ( $\mathrm{OR}=1.26,95 \%$ CI 1.10 to 1.45 ) and was higher in patients with HbAlc of $7 \%-8.9 \%$ 
Table 1 Comparison of clinical and metabolic variables in subjects with recently diagnosed type 2 diabetes by retinopathy

\begin{tabular}{|c|c|c|c|}
\hline & $\begin{array}{l}\text { DR } \\
n=213, n(\%)\end{array}$ & $\begin{array}{l}\text { No DR } \\
n=1019, n(\%)\end{array}$ & P value* \\
\hline Age at recruitment (years), mean (SD) & $50.9(9.2)$ & $51.6(10.2)$ & 0.343 \\
\hline Age at diabetes diagnosis (years), mean (SD) & $48.7(9.1)$ & $50.0(10.2)$ & 0.069 \\
\hline Sex (men) & $120(56.3)$ & $424(41.6)$ & $<0.001$ \\
\hline Diabetes duration (years) $\dagger$ & $2(0-4)$ & $1(0-3)$ & 0.0001 \\
\hline \multicolumn{4}{|l|}{ Diabetes duration (years) } \\
\hline$<1$ & $62(29.1)$ & $408(40.0)$ & $<0.001$ \\
\hline $1-2$ & $47(22.1)$ & $306(30.0)$ & \\
\hline $3-5$ & $104(48.8)$ & $305(29.9)$ & \\
\hline Hypertension $\ddagger$ & $95(44.6)$ & $343(33.7)$ & 0.002 \\
\hline $\mathrm{SBP}(\mathrm{mm} \mathrm{Hg})$ & $133.1(16.5)$ & $126.2(15.3)$ & $<0.0001$ \\
\hline $\mathrm{DBP}(\mathrm{mm} \mathrm{Hg})$ & $80.8(7.8)$ & $77.9(7.7)$ & $<0.0001$ \\
\hline BMI $\left(\mathrm{kg} / \mathrm{m}^{2}\right)$, media (SD) & $29.2(4.7)$ & $29.5(4.9)$ & 0.276 \\
\hline \multicolumn{4}{|l|}{ WC $(\mathrm{cm}) \dagger$} \\
\hline Men & $98.9(89.8-106.0)$ & $100.0(92.6-109.0)$ & 0.031 \\
\hline Women & $99.0(91.2-108.0)$ & $96.5(89.0-104.4)$ & 0.0001 \\
\hline Daily intake total calories (kcal) & $1568.0(1347.0-1885.0)$ & $1532.5(1266.0-1842.0)$ & 0.136 \\
\hline $\mathrm{HbA1c}(\%) \dagger$ & $9.0(7.2-11.1)$ & $7.4(6.3-10.1)$ & 0.0001 \\
\hline $\mathrm{HbA} 1 \mathrm{c}(\mathrm{mmol} / \mathrm{mol}) \dagger$ & $74.9(55.2-97.8)$ & $57.4(45.4-86.9)$ & 0.0001 \\
\hline \multicolumn{4}{|l|}{$\mathrm{HbA1c}(\%)$} \\
\hline$<7$ & $44(20.7)$ & $433(42.5)$ & $<0.001$ \\
\hline $7.0-8.9$ & $62(29.1)$ & $258(25.3)$ & \\
\hline$\geq 9$ & $107(50.2)$ & $328(32.2)$ & \\
\hline Fasting plasma glucose (mmol/L) $†$ & $9.2(6.8-13.2)$ & $7.0(5.8-9.8)$ & 0.0001 \\
\hline Triglycerides (mmol/L)† & $2.1(1.5-3.2)$ & $2.0(1.4-2.8)$ & 0.074 \\
\hline Total cholesterol $(\mathrm{mmol} / \mathrm{L}) \dagger$ & $5.0(4.3-5.7)$ & $4.9(4.2-5.6)$ & 0.352 \\
\hline LDL-C (mmol/L)† & $3.1(2.4-3.6)$ & $2.9(2.4-3.5)$ & 0.395 \\
\hline \multicolumn{4}{|l|}{$\mathrm{HDL}-\mathrm{C}(\mathrm{mmol} / \mathrm{L}) \dagger$} \\
\hline Men & $2.8(2.2-3.4)$ & $2.8(2.2-3.3)$ & 0.301 \\
\hline Women & $3.3(2.7-3.9)$ & $3.1(2.5-3.7)$ & 0.858 \\
\hline \multicolumn{4}{|l|}{ Albuminuria } \\
\hline Normal & $155(74.2)$ & $856(86.0)$ & $<0.001$ \\
\hline Microalbuminuria & $43(20.7)$ & $121(12.2)$ & \\
\hline Macroalbuminuria & $10(4.8)$ & $18(1.8)$ & \\
\hline \multicolumn{4}{|l|}{ Hypoglycaemic medication } \\
\hline None & $37(17.4)$ & $159(15.6)$ & 0.324 \\
\hline Oral drugs & $169(79.3)$ & $841(82.5)$ & \\
\hline Insulin with or without oral drugs & $7(3.3)$ & $19(1.9)$ & \\
\hline Antihypertensive medication§ & $53(55.8)$ & $239(69.7)$ & 0.011 \\
\hline Statins use & $21(9.9)$ & $151(14.8)$ & 0.058 \\
\hline Fibrate use & $22(10.3)$ & $107(10.5)$ & 0.941 \\
\hline \multicolumn{4}{|l|}{ Visual capacity in the better eye } \\
\hline Normal & $184(86.4)$ & $861(84.5)$ & 0.634 \\
\hline Mild impairment & $23(10.8)$ & $120(11.8)$ & \\
\hline Severe impairment & $6(2.8)$ & $31(3.0)$ & \\
\hline Blindness & $0(0.0)$ & $7(0.7)$ & \\
\hline
\end{tabular}

Missing values: BMI, 1; WC, 5; LDL-C, 2; total calorie intake, 27; albuminuria, 29.

*Pearson's $\chi^{2}$ or Fisher's test was used when appropriate. Student's t-test or Kruskal-Wallis test was used when appropriate.

†Median and 25 and 75 percentiles were calculated.

†From 438 patients with hypertension, 327 (74.7\%) were uncontrolled.

§Only for hypertensive subjects.

BMI, body mass index; DBP, diastolic blood pressure; DR, diabetic retinopathy; HbA1c, haemoglobin A1c; HDL-C, high-density lipoprotein cholesterol; LDL-C, low-density lipoprotein cholesterol; SBP, systolic blood pressure; WC, waist circumference. 


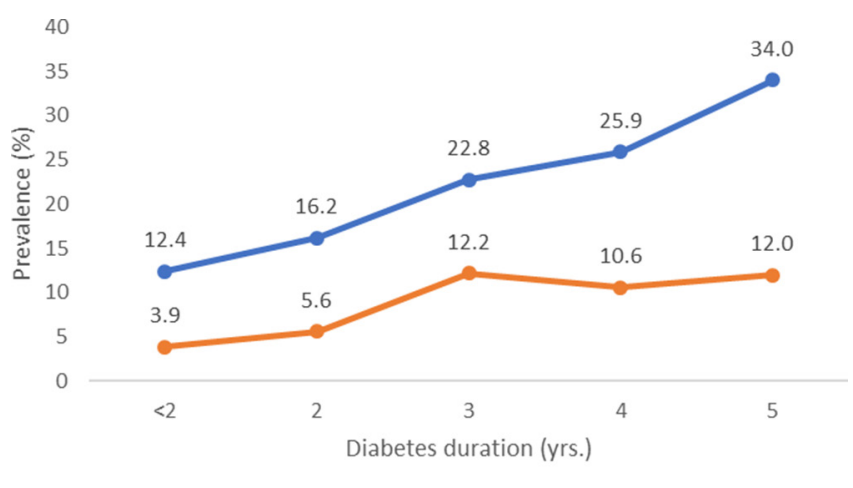

$\longrightarrow$ Diabetic retinopathy $\longrightarrow$ Macular oedema

Figure 1 Prevalence of diabetic retinopathy and diabetic macular oedema per year after diabetes diagnosis.

$(\mathrm{OR}=2.26,95 \%$ CI $1.15 \%$ to $4.41 \%)$ and in those with HbAlc of $\geq 9 \% \quad(\mathrm{OR}=2.38,95 \% \mathrm{CI} 1.25 \%$ to $4.50 \%)$ compared with patients with HbAlc of $<7 \%$. The probability of DME was higher in individuals with higher SBP (OR per $5 \mathrm{~mm} \mathrm{Hg}=1.15$, 95\% CI 1.07 to 1.23 ) and in those with albuminuria (OR=2.45, 95\% CI 1.46 to 4.09 ) after adjustment for age at the time of diabetes diagnosis and use of antihypertensive drugs. In the stratified analysis by diabetes duration, the association between DME and HbAlc categories, SBP and albuminuria remained significant in both strata (table 4).

Finally, in a model comparing the magnitude of the association of the same risk factors mentioned previously with DR alone and DR with concomitant DME, similar results for $\mathrm{HbA} 1 \mathrm{c}$ of $7 \%-8.9 \%$ (OR=1.96, 95\% CI $1.17 \%$ to $3.27 \%$ and $\mathrm{OR}=2.65,95 \%$ CI $1.35 \%$ to $5.19 \%$, respectively) and HbA1c of $\geq 9 \%$ (OR=2.75, 95\% CI $1.72 \%$ to $4.40 \%$ and $\mathrm{OR}=3.46,95 \% \mathrm{CI} 1.86 \%$ to $6.44 \%$, respectively) were observed.

\section{DISCUSSION}

In this paper, we describe the prevalence of DR and DME in patients with recent diagnosis of diabetes, specifically a highly selected group of individuals with time since diagnosis of 5 years or less and no chronic microvascular and macrovascular complications, among other inclusion criteria. Because of the comprehensive ophthalmological approach (fundus photography and clinical examination by an expert grader), a highly accurate and detailed diagnosis was made in comparison with the conventional screening programme that include only non-mydriatic fundus photography. ${ }^{20}$

We found that $17.3 \%$ of patients had some degree of DR; this percentage is similar to that reported by Lee and Sum, ${ }^{21}$ who described an $18.2 \%$ prevalence in patients from Hong Kong with a recent ( $\leq 1$ year) diabetes diagnosis. However, in that population, nine dilated images of each eye were taken; with this approach, more retinal area was examined, and thus, retinal findings in the periphery of the retina, not detected in our study, may account for a higher DR prevalence in that study. In other paper, Yau et al described a prevalence of $21.1 \%$ in patients with diabetes diagnosis shorter than 10 years in a population including patients from the USA, Australia, Europe and Asia. This prevalence agrees with the prevalence reported in our study; nevertheless, a specific analysis of patients with diagnosis shorter than 5 years was not performed.

The global prevalence of chronic diseases is increasing and seriously threatening low-income countries' ability to improve the health of their populations. The increase of lifestyle-related chronic diseases in these countries is the result of a complex combination of social, economic and behavioural factors. In addition, with limited resources and less awareness about chronic diseases, diagnosis of diabetes is often made late, so there is a long time span between onset of diabetes and detection of complications, which accounts for the high rate of DR an DME observed in our study. ${ }^{22}$ Genetic factors may also play a role, as Mexican individuals have been shown to have greater prevalence of RD compared with non-Hispanics, particularly in studies conducted in the USA.

The prevalence of DME in our study was $6.7 \%$, ranging between $3.9 \%$ in persons at $<1$ year and $12.0 \%$ in those at 5 years from diabetes diagnosis. This subgroup is important because it highlights the fact that even with an early diagnosis, the risk of visual impairment in subsequent stages of life does not disappear. In this population, an early detection may prompt both the clinical team and the patient to improve the metabolic control and thus reduce the probability of further microvascular damage to the retina that might lead to visual loss. In 2014, Pezzullo et a ${ }^{23}$ estimated an overall prevalence of DR in Mexico was 3.3\% (2681562 individuals), of whom $0.1 \%$ were blind.

DME is the most important cause of visual impairment in persons with diabetes, and this fact is particularly relevant in our population for the healthcare system, as the access and cost of treatment is substantial. The direct costs of DR treatment were calculated at over 120 million dollars and the indirect costs, at nearly 30 million, most of which are attributable to informal care. Published data on DME prevalence in early diabetes show some variation. Yau et al $t^{t}$ reported a $3.2 \%$ prevalence of DME in patients with diabetes diagnosis shorter than 10 years, whereas Martinell et al reported a $11 \%$ prevalence in a group of Swedish patients at the time of diagnosis. ${ }^{24}$ As for our study, differences with other populations could be partially accounted by genetic predisposition to DME and higher risk of proliferative DR in Hispanics, particularly of Mexican ancestry. ${ }^{25}$

In general, risk factors for DR can be broadly divided into modifiable and non-modifiable factors. Some modifiable risk factors are hyperglycaemia, hypertension, hyperlipidaemia and obesity, whereas duration of diabetes, sex, ethnicity, puberty and pregnancy are nonmodifiable risk factors. ${ }^{26}$ DME shares many risk factors with DR; nevertheless, there are some differences. DME is more common in people with type 2 diabetes than in those with type 1 diabetes ${ }^{27}$; also, diabetes duration 
Table 2 Prevalence of DR and ME by several risk factors in subjects with recently diagnosed type 2 diabetes

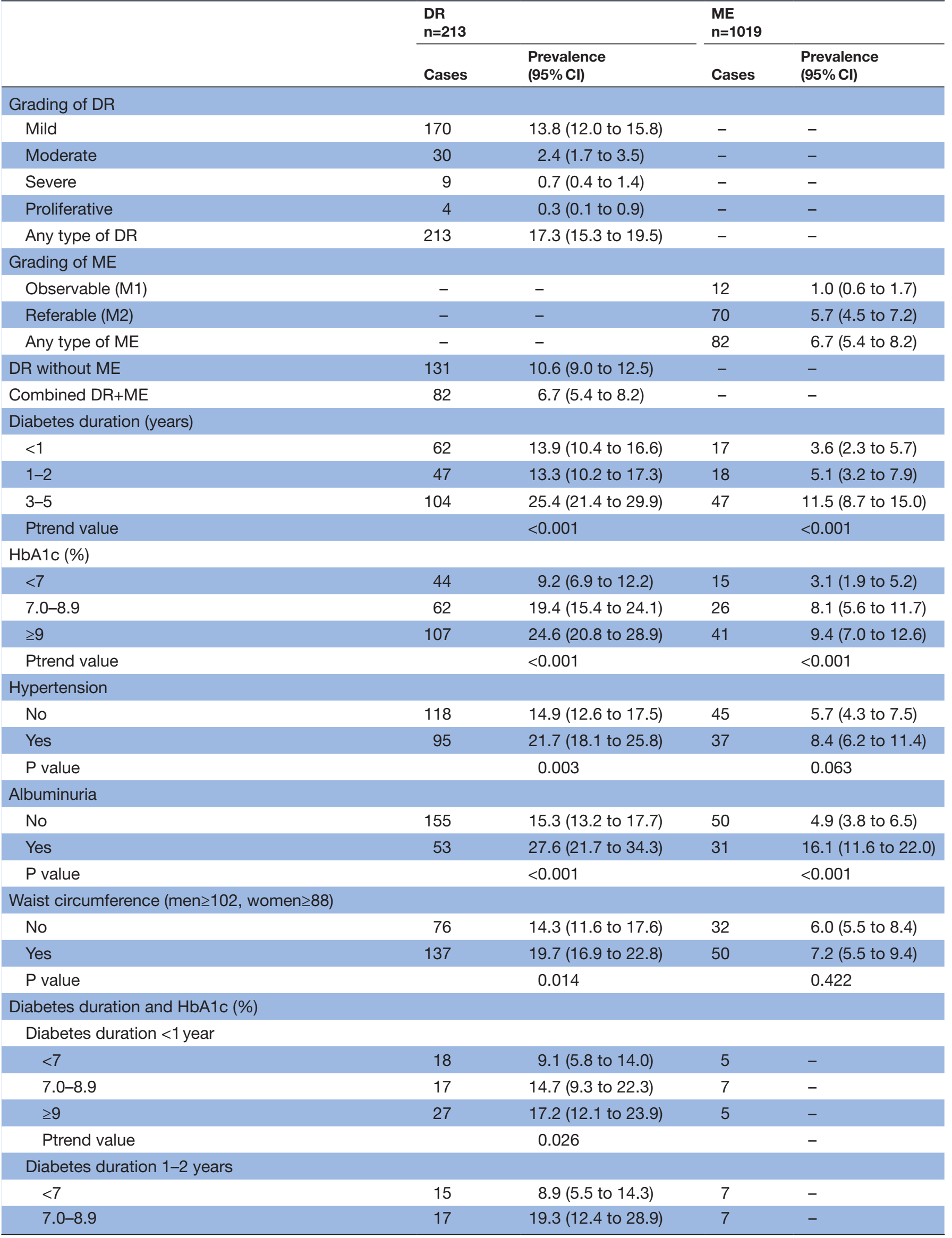




\begin{tabular}{|c|c|c|c|c|}
\hline & \multicolumn{2}{|l|}{$\begin{array}{l}\text { DR } \\
n=213\end{array}$} & \multicolumn{2}{|l|}{$\begin{array}{l}\text { ME } \\
n=1019\end{array}$} \\
\hline & Cases & $\begin{array}{l}\text { Prevalence } \\
(95 \% \mathrm{Cl})\end{array}$ & Cases & $\begin{array}{l}\text { Prevalence } \\
(95 \% \mathrm{Cl})\end{array}$ \\
\hline$\geq 9$ & 15 & $15.5(9.5$ to 24.1$)$ & 4 & - \\
\hline Ptrend value & & 0.081 & & - \\
\hline \multicolumn{5}{|l|}{ Diabetes duration $3-5$ years } \\
\hline$<7$ & 11 & 9.8 (5.5 to 16.9$)$ & 3 & 2.7 (0.9 to 8.0$)$ \\
\hline $7.0-8.9$ & 28 & 24.1 (17.2 to 32.7$)$ & 12 & $10.3(6.0$ to 17.3$)$ \\
\hline$\geq 9$ & 65 & 35.9 (29.3 to 43.2$)$ & 32 & 17.7 (12.8 to 23.9$)$ \\
\hline Ptrend value & & $<0.001$ & & $<0.001$ \\
\hline \multicolumn{5}{|c|}{ Diabetes duration and hypertension (\%) } \\
\hline \multicolumn{5}{|c|}{ Diabetes duration $<1$ year } \\
\hline No & 40 & 12.5 (9.3 to 16.6$)$ & 11 & 3.4 (1.9 to 6.1$)$ \\
\hline Yes & 22 & $14.6(9.8$ to 21.1$)$ & 6 & 4.0 (1.8 to 8.6$)$ \\
\hline$P$ value & & 0.544 & & 0.776 \\
\hline \multicolumn{5}{|l|}{ Diabetes duration $1-2$ years } \\
\hline No & 28 & 11.6 (8.1 to 16.2$)$ & 11 & 4.5 (2.5 to 8.0$)$ \\
\hline Yes & 19 & 17.1 (11.2 to 25.3$)$ & 7 & $6.3(3.1$ to 12.6$)$ \\
\hline$P$ value & & 0.157 & & 0.487 \\
\hline \multicolumn{5}{|l|}{ Diabetes duration $3-5$ years } \\
\hline No & 50 & 21.5 (16.7 to 27.2$)$ & 23 & $9.9(6.6$ to 14.4$)$ \\
\hline Yes & 54 & 30.7 (24.3 to 38.9$)$ & 24 & 13.6 (9.3 to 19.5$)$ \\
\hline$P$ value & & 0.035 & & 0.239 \\
\hline \multicolumn{5}{|c|}{ Diabetes duration and albuminuria (\%) } \\
\hline \multicolumn{5}{|l|}{ Diabetes duration $<1$ year } \\
\hline Non-albuminuria & 53 & $13.1(10.1$ to 16.7$)$ & 12 & $3.0(1.7$ to 5.1$)$ \\
\hline Albuminuria & 9 & 16.4 (8.7 to 28.6$)$ & 5 & 9.1 (3.8 to 20.0$)$ \\
\hline$P$ value & & 0.505 & & 0.032 \\
\hline \multicolumn{5}{|l|}{ Diabetes duration $1-2$ years } \\
\hline Non-albuminuria & 32 & $11.3(8.1$ to 15.6$)$ & 10 & 3.5 (1.9 to 6.5$)$ \\
\hline Albuminuria & 15 & 23.4 (14.7 to 35.3$)$ & 8 & 12.5 (6.4 to 23.1$)$ \\
\hline$P$ value & & 0.013 & & 0.006 \\
\hline \multicolumn{5}{|l|}{ Diabetes duration $3-5$ years } \\
\hline Non-albuminuria & 70 & 21.6 (17.5 to 26.4$)$ & 28 & $8.6(6.0$ to 12.2$)$ \\
\hline Albuminuria & 29 & 39.7 (29.2 to 51.3$)$ & 18 & 24.7 (16.1 to 35.8$)$ \\
\hline$P$ value & & 0.001 & & $<0.001$ \\
\hline Age-adjusted and sex-adjusted & 213 & 17.4 (15.3 to 19.6$)$ & 82 & 6.6 (5.4 to 8.2$)$ \\
\hline
\end{tabular}

Prevalence and its $95 \% \mathrm{Cl}$ were estimated by logistic regression models. DR: unilateral in 97 cases, bilateral in 116 cases. Diabetic macular oedema: unilateral in 41 cases, bilateral in 41 cases.

Missing values: albuminuria, 29.

$\mathrm{DR}$, diabetic retinopathy; HbA1c, haemoglobin A1c; ME, macular oedema.

may not be as strongly associated, and so is the case for puberty and pregnancy. ${ }^{28}$

Among the risk factors associated with DR and DME in our study, diabetes duration, HbA1c and albuminuria were observed. ${ }^{29}$ Hyperglycaemia is the key modifiable risk factor for DR and DME. Hyperglycaemia results in the accumulation of advanced glycation end products and free oxygen radicals, which activate the inflammatory pathways involved. ${ }^{30} \mathrm{~A}$ longer duration of diabetes increases the amount of time the retina is exposed to hyperglycaemia-induced damage. ${ }^{31}$ After stratification by diabetes duration, those with $3-5$ years from diagnosis 
Table 3 Risk factors associated with the prevalence of diabetic retinopathy in subjects with recently diagnosed type 2 diabetes stratified by diabetes duration

\begin{tabular}{|c|c|c|c|c|}
\hline & \multicolumn{2}{|l|}{ Whole sample } & \multicolumn{2}{|c|}{ Stratified by duration of diabetes } \\
\hline & & & $<1-2$ years & $3-5$ years \\
\hline & $\begin{array}{l}\text { Unadjusted } \\
\text { OR }(95 \% \mathrm{Cl})\end{array}$ & $\begin{array}{l}\text { Adjusted } \\
\text { OR }(95 \% \mathrm{Cl})\end{array}$ & $\begin{array}{l}\text { Adjusted } \\
\text { OR }(95 \% \mathrm{Cl})\end{array}$ & $\begin{array}{l}\text { Adjusted } \\
\text { OR }(95 \% \mathrm{Cl})\end{array}$ \\
\hline $\begin{array}{l}\text { Age at diabetes diagnosis (per } \\
5 \text { years) }\end{array}$ & $0.93(0.88$ to 0.99$)$ * & $0.93(0.85$ to 1.00$)$ & $0.89(0.82$ to 0.98$)$ * & $1.00(0.86$ to 1.16$)$ \\
\hline Sex (men) & $1.81(1.34$ to 2.44$) * * *$ & $1.81(1.33$ to 2.46$) * \star *$ & $1.80(1.18$ to 2.73$)$ ** & $1.83(1.14$ to 2.95$) *$ \\
\hline Duration of diabetes (per year) & $1.27(1.16$ to 1.40$) * * *$ & $1.20(1.10 \text { to } 1.32)^{* * *}$ & - & - \\
\hline \multicolumn{5}{|l|}{ Duration of diabetes (years) } \\
\hline$<1$ & Reference & - & - & - \\
\hline $1-2$ & 1.01 (0.67 to 1.52$)$ & - & - & - \\
\hline $3-5$ & $2.24(1.58$ to 3.18$)$ *** & - & - & - \\
\hline $\mathrm{HbA1c}(\mathrm{mmol} / \mathrm{mol})$ & $1.15(1.09 \text { to } 1.21)^{* \star *}$ & - & - & - \\
\hline \multicolumn{5}{|l|}{$\mathrm{HbA1c}(\%)$} \\
\hline$<7$ & Reference & Reference & Reference & Reference \\
\hline $7.0-8.9$ & $2.17(1.33 \text { to } 3.53)^{\star *}$ & $2.19(1.43 \text { to } 3.35)^{\star \star \star}$ & $1.86(1.11 \text { to } 3.12)^{\star}$ & $3.37(1.52 \text { to } 7.50)^{\star \star}$ \\
\hline$\geq 9$ & $3.07(2.13 \text { to } 4.42)^{\star \star \star}$ & $2.98(2.01 \text { to } 4.42)^{\star \star \star}$ & $1.94(1.18 \text { to } 3.19)^{\star \star}$ & $6.22(2.96 \text { to } 13.09)^{\star \star \star}$ \\
\hline Hypertension & $1.59(1.18 \text { to } 2.14)^{\star \star}$ & - & - & - \\
\hline SBP (per 5 mm Hg) & $1.14(1.09$ to 1.19$)$ *** & $1.16(1.10$ to 1.22$)$ *** & $1.13(1.06 \text { to } 1.21)^{* \star \star}$ & $1.21(1.11 \text { to } 1.32)^{* \star *}$ \\
\hline DPB (per 5 mm Hg) & $1.28(1.16$ to 1.40$) * * *$ & - & & \\
\hline Triglycerides $\geq 1.68 \mathrm{mmol} / \mathrm{L}$ & 1.25 (0.91 to 1.71$)$ & - & - & - \\
\hline Albuminuria & $2.11(1.47$ to 3.02$)$ *** & - & - & - \\
\hline Antihypertensive drugs & 1.08 (0.77 to 1.52$)$ & 0.95 (0.64 to 1.41$)$ & $1.03(0.60$ to 1.77$)$ & 0.85 (0.47 to 1.55$)$ \\
\hline Statin use & 1.21 (0.70 to 2.11$)$ & - & - & - \\
\hline
\end{tabular}

Simple and multiple robust logistic regression analysis was used to estimate ORs and their $95 \% \mathrm{Cls}$.

Whole sample, $n=1232$; subsample with diabetes duration of $<1-2$ years, $n=823$; and subsample with a diabetes duration from 3 to 5 years,

$\mathrm{n}=409$. Missing values: albuminuria, 29 .

${ }^{*} \mathrm{P}<0.05,{ }^{* *} \mathrm{P}<0.01,{ }^{* \star *} \mathrm{P}<0.001$.

DBP, diastolic blood pressure; HbA1c, haemoglobin A1c; SBP, systolic blood pressure.

had about a twofold probability of having DR by high levels of HbA1c compared with those with $<3$ years. Several studies have consistently shown that hyperglycaemia is the main risk factor for DR and DME in both type 1 and type 2 diabetes. ${ }^{82-36}$ Additionally, higher HbAlc has been associated with both incidence and progression of DR over a 4-year follow-up in patients with type 2 diabetes, including proliferative DR. ${ }^{37}$ Other studies have stressed that tight glycaemic control may be effective in preventing or delaying the onset of DR, but rapid reductions in HbAlc should be avoided because of the adverse effects of hypoglycaemia. ${ }^{38}$ Early intensive glycaemic control can reduce the risk of DME by almost half, and the effect is long lasting, thus underscoring the importance of early and effective intervention. However, the reduction in risk of DME was less than that for progression to proliferative DR and decreased with time. This may occur most likely because the pathophysiology of proliferative DR is related to ischaemia, and hyperglycaemia might have stronger epigenetic effects on ischaemic-related pathways. ${ }^{39}$
Regarding hypertension and SBP, they were steadily associated with both DR and DME, and the association for SBP was slightly higher in those with longer diabetes duration. Hypertension leads to additional damage to retinal vessels by hyperperfusion, shearing forces and increased oedema formation. ${ }^{40}$ Several clinical trials have shown the effectiveness of blood pressure control in the reduction on the risk of DR in both type 1 and type 2 diabetes. Specifically, in the UK Prospective Diabetes Study (UKPDS) ${ }^{41}$ patients with type 2 diabetes who were subjected to strict blood pressure control reduced their risk of DR up to $34 \%$. Other clinical trials as the EURODIAB (European Diabetes Centres Study) ${ }^{42}$ and DIRECT (Diabetes Remission Clinical Trial) obtained as well a significant reduction on the progression of DR (50\% and $18 \%$, respectively). ${ }^{43}$

As for albuminuria, it was strongly associated with DME in those with either shorter or longer diabetes duration. There is evidence about the increased prevalence of proliferative DR with presence of microalbuminuria or macroalbuminuria compared with normoalbuminuria in 
Table 4 Risk factors associated with prevalence of diabetic macular oedema in patients with recently diagnosed type 2 diabetes stratified by diabetes duration

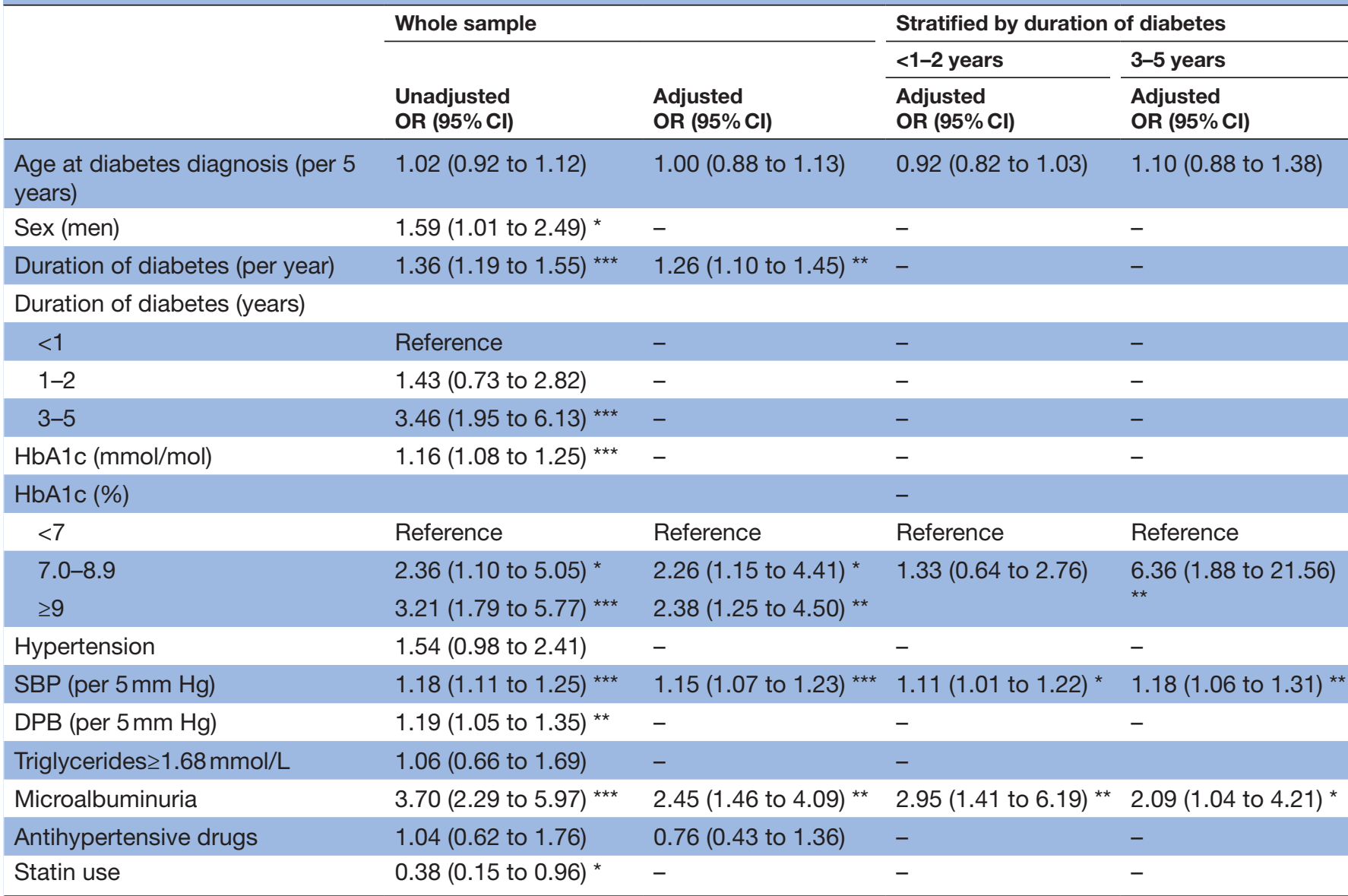

Simple and multiple robust logistic regression analysis was used to estimate ORs and their $95 \% \mathrm{Cls}$. In models stratified by diabetes duration, $\mathrm{HbA} 1 \mathrm{c}$ categories were $<7$ and $\geq 7$.

Whole sample, $n=1203$; subsample with diabetes duration $<1-2$ years, $n=806$; and subsample with a diabetes duration from 3 to 5 years, $\mathrm{n}=397$. Missing values: microalbuminuria, 29.

${ }^{*} \mathrm{P}<0.05,{ }^{* *} \mathrm{P}<0.01,{ }^{* *} \mathrm{P}<0.001$.

DBP, diastolic blood pressure; HbA1c, haemoglobin A1c; SBP, systolic blood pressure.

patients with type 1 diabetes. ${ }^{44}$ Other studies have shown that DR is related to urine albumin excretion and lower glomerular filtration rate in patients with type 2 diabetes even after adjustment for diabetes duration. ${ }^{45}$

Our study has some limitations. It was performed in an outpatient hospital-based population, so results are not representative of other clinical settings. Also, there was a selection bias due to the strict inclusion criteria, which precluded patients with microvascular complications from joining the comprehensive care programme; the probability of DR or DME may be even greater in persons recently diagnosed with diabetes. These facts highlight the urgent need to implement cost-efficient screening strategies to increase coverage of eye examination in people with type 2 diabetes and the necessity to construct an adequate infrastructure for prompt referral and treatment of these individuals who may otherwise suffer lifelong disability. In addition, using the worse eye in terms of retinopathy severity to assign a diagnosis for an individual patient may represent another limitation. However, doing so provides an estimate of the prevalence of the disease severity in this particular set of patients, whereas doing the opposite may underestimate it.

In summary, knowledge of prevalence of DR and DME and of their associated risk factors in recently diagnosed persons may contribute to developing more cost-effective diabetic eye disease screening programmes. Interventions in persons with recent diabetes diagnosis are fundamental, particularly in countries like Mexico, where the prevalence of diabetes is increasing. Large efforts are needed to prevent the visual impairment and blindness secondary to DR and DME, which in turn could reduce health expenditure costs, increase the efficiency of existing infrastructure and human resources, and finally improve the clinical care and quality of life of patients with diabetes.

Author affiliations

${ }^{1}$ Departamento de Córnea y Cirugía Refractiva, Instituto de Oftalmología Fundación Conde de Valenciana IAP, Ciudad de México, México

${ }^{2}$ Instituto de Oftalmología Fundación Conde de Valenciana IAP, Ciudad de México, México 
${ }^{3}$ Centro de Atención Integral del Paciente con Diabetes, Instituto Nacional de Ciencias Médicas y Nutrición Salvador Zubirán, Ciudad de México, México ${ }^{4}$ Departamento de Endocrinología y Metabolismo, Instituto Nacional de Ciencias Médicas y Nutrición Salvador Zubirán, Ciudad de México, México ${ }^{5}$ Instituto Nacional de Ciencias Médicas y Nutrición Salvador Zubirán, Ciudad de México, México

${ }^{6}$ Departamento de Epidemiología Ocular y Salud Visual, Instituto de Oftalmología Fundación Conde de Valenciana IAP, Ciudad de México, México

${ }^{7}$ Dirección General de Epidemiología, Ciudad de México, México

Acknowledgements The authors thank the National Institute of Medical Sciences and Nutrition, Salvador Zubiran, and the Institute of Ophthalmology Conde de Valenciana in Mexico for their technical assistance and administrative support, and are indebted to all persons who agreed to participate in the study.

Contributors EOG-H and AJ-C designed the study, researched the data, conducted the data analysis and wrote the manuscript. DR-D-L-P researched the data, reviewed and edited the manuscript and contributed to the discussion. CAA-S, SH-J and DK-S reviewed the manuscript and contributed to the discussion. AJ-C is the guarantor of this work and, as such, had full access to all the data in the study and takes responsibility for the integrity of the data and the accuracy of the data analysis.

Funding This study was supported by the National Institute of Medical Sciences and Nutrition, Salvador Zubiran, by the Institute of Ophthalmology Conde de Valenciana in México City, México, and by the Fondo Sectorial de Investigación en Salud y Seguridad Social SS/IMSS/ISSSTE-CONACYT, National Council of Science and Technology from Mexico (grant FOSISS-SALUD-2014-01-234409).

Competing interests None declared.

Patient consent for publication Not required.

Ethics approval The institutional review boards of research, ethics, and biosecurity from the National Institute of Medical Sciences and Nutrition, Salvador Zubiran, and the Institute of Ophthalmology Conde de Valenciana approved the study protocol. All participants signed written informed consent.

Provenance and peer review Not commissioned; externally peer reviewed.

Open access This is an open access article distributed in accordance with the Creative Commons Attribution Non Commercial (CC BY-NC 4.0) license, which permits others to distribute, remix, adapt, build upon this work non-commercially, and license their derivative works on different terms, provided the original work is properly cited, appropriate credit is given, any changes made indicated, and the use is non-commercial. See: http://creativecommons.org/licenses/by-nc/4.0/.

ORCID ID

Aida Jimenez-Corona http://orcid.org/0000-0001-9565-4178

\section{REFERENCES}

1 International Diabetes Federation. IDF diabetes atlas. 8th edn. Brussels, Belgium: International Diabetes Federation. Brussels, Belgium, 2017: 1-147.

2 Rojas-Martínez R, Basto-Abreu A, Aguilar-Salinas CA, et al. [Prevalence of previously diagnosed diabetes mellitus in Mexico.]. Salud Publica Mex 2018;60:224-32.

3 Meza R, Barrientos-Gutierrez T, Rojas-Martinez R, et al. Burden of type 2 diabetes in Mexico: past, current and future prevalence and incidence rates. Prev Med 2015;81:445-50.

4 Yau JWY, Rogers SL, Kawasaki R, et al. Global prevalence and major risk factors of diabetic retinopathy. Diabetes Care 2012;35:556-64.

5 Polack S, Yorston D, López-Ramos A, et al. Rapid assessment of avoidable blindness and diabetic retinopathy in Chiapas, Mexico. Ophthalmology 2012;119:1033-40.

6 Lima-Gómez V, Blanco-Hernández DMR, Muñoz-lbarra P, et al. Severity distribution of diabetic macular edema at the time of diagnosis. Cir Cir 2011;79:491-7.

7 Tapp RJ, Shaw JE, Harper CA, et al. The prevalence of and factors associated with diabetic retinopathy in the Australian population. Diabetes Care 2003;26:1731-7.

8 Wong TY, Cheung N, Tay WT, et al. Prevalence and risk factors for diabetic retinopathy: the Singapore Malay eye study. Ophthalmology 2008;115:1869-75.

9 Magliah SF, Bardisi W, Al Attah M, et al. The prevalence and risk factors of diabetic retinopathy in selected primary care centers during the 3-year screening intervals. J Family Med Prim Care 2018;7:975-81.
10 Sasongko MB, Wong TY, Nguyen TT, et al. Serum apolipoprotein $\mathrm{Al}$ and $\mathrm{B}$ are stronger biomarkers of diabetic retinopathy than traditional lipids. Diabetes Care 2011;34:474-9.

11 Squirrell D, Bhola R, Bush J. A prospective, case controlled study of the natural history of diabetic retinopathy and maculopathy after uncomplicated phacoemulsification cataract surgery in patients with type 2 diabetes. Br J Ophthalmol 2002;86:565-71.

12 Lim LS, Lamoureux E, Saw SM, et al. Are myopic eyes less likely to have diabetic retinopathy? Ophthalmology 2010;117:524-30.

13 Wong TY, Cheung CMG, Larsen M, et al. Diabetic retinopathy. Nat Rev Dis Primers 2016;2:16012.

14 Keech AC, Mitchell P, Summanen PA, et al. Effect of fenofibrate on the need for laser treatment for diabetic retinopathy (field study): a randomised controlled trial. Lancet 2007;370:1687-97.

15 Hernandez-Jimenez S, Garcia-Ulloa C, Mehta R, et al. Innovative models for the Empowerment of patients with type 2 diabetes: the CAIPaDi program. Recent Pat Endocr Metab Immune Drug Discov 2014:8:202-9.

16 Expert Committee on the Diagnosis and Classification of Diabetes Mellitus. Report of the expert Committee on the diagnosis and classification of diabetes mellitus. Diabetes Care 2003;26 Suppl 1:5-20.

17 Chobanian AV, Bakris GL, Black HR, et al. The seventh report of the joint National Committee on prevention, detection, evaluation, and treatment of high blood pressure: the JNC 7 report. JAMA 2003;289:2560-72.

18 Dandona L, Dandona R. Revision of visual impairment definitions in the International statistical classification of diseases. BMC Med 2006;4:1-7.

19 National Health Service (NHS). Scottish diabetic retinopathy screening collaborative. Available: http://www.ndrs-wp.scot.nhs.uk/

20 National Health Service (NHS). The NHS diabetic eye screening programme revised grading definitions, 2012. Available: http://www. diabeticeye.screening.nhs.uk/gradingcriteria

21 Lee KMC, Sum WMR. Prevalence of diabetic retinopathy in patients with recently diagnosed diabetes mellitus. Clin Exp Optom 2011;94:371-5.

22 Nugent R. Chronic diseases in developing countries: health and economic burdens. Ann N Y Acad Sci 2008;1136:70-9.

23 Pezzullo L, Cheung S, Tay-Teo K, et al. El costo económico $\mathrm{Y}$ carga de las Enfermedades oculares $Y$ de la ceguera evitable en México. Rev Mex Oftalmol 2014;88:2-30.

24 Martinell M, Dorkhan M, Stålhammar J, et al. Prevalence and risk factors for diabetic retinopathy at diagnosis (DRAD) in patients recently diagnosed with type 2 diabetes (T2D) or latent autoimmune diabetes in the adult (LADA). J Diabetes Complications 2016;30:1456-61.

25 Chen JL, Luviano DM, Chen JC, et al. Comparison of diabetic retinopathy phenotype between Latinos and blacks. J Diabetes Complications 2009;23:371-5.

26 Ting DSW, Cheung GCM, Wong TY. Diabetic retinopathy: global prevalence, major risk factors, screening practices and public health challenges: a review. Clin Experiment Ophthalmol 2016;44:260-77.

27 Klein R, Klein BE, Moss SE, et al. The Wisconsin epidemiologic study of diabetic retinopathy. XV. The long-term incidence of macular edema. Ophthalmology 1995;102:7-16.

28 Klein R, Knudtson MD, Lee KE, et al. The Wisconsin epidemiologic study of diabetic retinopathy XXIII: the twenty-five-year incidence of macular edema in persons with type 1 diabetes. Ophthalmology 2009;116:497-503.

29 Antonetti DA, Barber AJ, Bronson SK, et al. Diabetic retinopathy: seeing beyond glucose-induced microvascular disease. Diabetes 2006;55:2401-11.

30 Behl T, Kaur I, Kotwani A. Implication of oxidative stress in progression of diabetic retinopathy. Surv Ophthalmol 2016;61:187-96.

31 Klein R, Klein BE, Moss SE, et al. The Wisconsin epidemiologic study of diabetic retinopathy. III. prevalence and risk of diabetic retinopathy when age at diagnosis is 30 or more years. Arch Ophthalmol 1984;102:527-32.

32 Klein R, Klein BE, Moss SE, et al. The Wisconsin epidemiologic study of diabetic retinopathy: XVII. The 14-year incidence and progression of diabetic retinopathy and associated risk factors in type 1 diabetes. Ophthalmology 1998;105:1801-15.

33 Jin P, Peng J, Zou H, et al. The 5-year onset and regression of diabetic retinopathy in Chinese type 2 diabetes patients. PLoS One 2014:9:e113359.

34 Pradeepa R, Anjana RM, Unnikrishnan R, et al. Risk factors for microvascular complications of diabetes among South Indian subjects with type 2 Diabetes-The Chennai urban rural 
epidemiology study (cures) eye Study-5. Diabetes Technol Ther 2010;12:755-61.

35 Tam VHK, Lam EPK, Chu BCY, et al. Incidence and progression of diabetic retinopathy in Hong Kong Chinese with type 2 diabetes mellitus. J Diabetes Complications 2009;23:185-93.

36 Cheng YJ, Gregg EW, Geiss LS, et al. Association of A1c and fasting plasma glucose levels with diabetic retinopathy prevalence in the U.S. population: implications for diabetes diagnostic thresholds. Diabetes Care 2009;32:2027-32.

37 Harris Nwanyanwu K, Talwar N, Gardner TW, et al. Predicting development of proliferative diabetic retinopathy. Diabetes Care 2013;36:1562-8.

38 Shurter A, Genter P, Ouyang D, et al. Euglycemic progression: worsening of diabetic retinopathy in poorly controlled type 2 diabetes in minorities. Diabetes Res Clin Pract 2013;100:362-7.

39 Tan GS, Cheung N, Simó R, et al. Diabetic macular oedema. Lancet Diabetes Endocrinol 2017;5:143-55.

40 Guan K, Hudson C, Wong T, et al. Retinal hemodynamics in early diabetic macular edema. Diabetes 2006;55:813-8.
41 Matthews DR, Stratton IM, Aldington SJ, et al. Risks of progression of retinopathy and vision loss related to tight blood pressure control in type 2 diabetes mellitus: UKPDS 69. Arch Ophthalmol 2004;122:1631-40.

42 Chaturvedi N, Sjolie AK, Stephenson JM, et al. Effect of lisinopril on progression of retinopathy in normotensive people with type 1 diabetes. The EUCLID Study Group. EURODIAB controlled trial of lisinopril in insulin-dependent diabetes mellitus. Lancet 1998;351:28-31.

43 Chaturvedi N, Porta M, Klein R, et al. Effect of candesartan on prevention (DIRECT-Prevent 1) and progression (DIRECT-Protect 1) of retinopathy in type 1 diabetes: randomised, placebo-controlled trials. The Lancet 2008;372:1394-402.

44 Parving $\mathrm{H}-\mathrm{H}$, Hommel E, Mathiesen E, et al. Prevalence of microalbuminuria, arterial hypertension, retinopathy, and neuropathy in patients with insulin dependent diabetes. BMJ 1988;296:156-60.

45 Trevisan R, Vedovato M, Mazzon C, et al. Concomitance of diabetic retinopathy and proteinuria accelerates the rate of decline of kidney function in type 2 diabetic patients. Diabetes Care 2002;25:2026-31. 